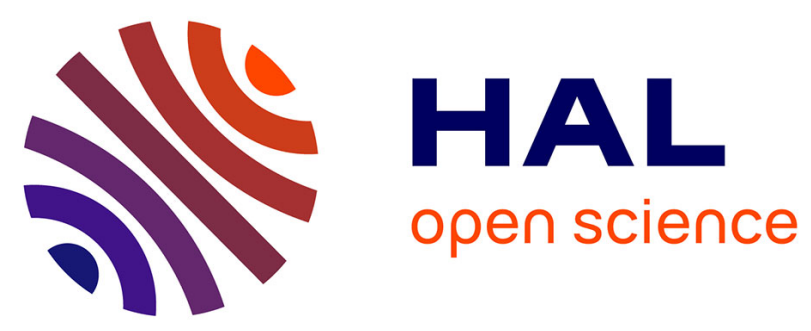

\title{
Simulation Method for Evaluation of Productivity and Energy Consumption Concerning Production Line for Injection Molding Machines
}

\author{
Rio Takasaki, Hironori Hibino, Kazuhide Kaifuku, Keitaro Nishitani
}

\section{To cite this version:}

Rio Takasaki, Hironori Hibino, Kazuhide Kaifuku, Keitaro Nishitani. Simulation Method for Evaluation of Productivity and Energy Consumption Concerning Production Line for Injection Molding Machines. IFIP International Conference on Advances in Production Management Systems (APMS), Sep 2017, Hamburg, Germany. pp.496-504, 10.1007/978-3-319-66926-7_57 . hal-01707260

\author{
HAL Id: hal-01707260 \\ https://hal.inria.fr/hal-01707260
}

Submitted on 12 Feb 2018

HAL is a multi-disciplinary open access archive for the deposit and dissemination of scientific research documents, whether they are published or not. The documents may come from teaching and research institutions in France or abroad, or from public or private research centers.
L'archive ouverte pluridisciplinaire HAL, est destinée au dépôt et à la diffusion de documents scientifiques de niveau recherche, publiés ou non, émanant des établissements d'enseignement et de recherche français ou étrangers, des laboratoires publics ou privés. 


\title{
Simulation method for evaluation of productivity and energy consumption concerning production line for injection molding machines.
}

\author{
Rio Takasaki ${ }^{1}$, Hironori Hibino ${ }^{1}$, Kazuhide Kaifuku², and Keitaro Nishitani ${ }^{1}$ \\ ${ }^{1}$ Tokyo University of Science, 2641 Yamazaki, Noda, Chiba, Japan \\ hibino@rs.tus.ac.jp \\ ${ }^{2}$ Toyota Boshoku Corporation, 1-1 Toyoda-cho, Kariya-shi, Aichi, Japan
}

\begin{abstract}
Methods for evaluating productivity and energy consumption simultaneously have been getting significant interest in the industry. In particular, although injection molding machines are important system components for production in plastic molding, a method for simultaneously evaluating their productivity and energy consumption has not been established. Therefore, we propose a simulation method that is based on a state transition model containing state transitions and states of machines in an injection molding production line.
\end{abstract}

Keywords: Manufacturing system simulation, Injection molding machine, Modeling, Energy consumption, Productivity.

\section{Introduction}

In the industrial world, on account of the revision of the "Act on the Rational Use of Energy" which was implemented in Japan in April 2014, a decrease of more than 1\% of the annual average energy consumption was systematically implemented. In the plastics industry, more than $90 \%$ parts are produced using injection molding machines. An injection molding machine involves processes that consume large amounts of energy, such as material plasticizing, part cooling, and opening and closing of molding die with high-pressure clamping. Therefore, the energy consumption per a part in manufacturing tends to be high. Moreover, the production line includes, in general, injection molding machines and several auxiliary machines that are used to improve productivity or maintain the product quality. Since injection molding and auxiliary machines work in series, the relations among processes in the production line are complicated. Currently, the relations between the states of machine and their transitions are not well organized. This causes difficulties in improving the productivity and energy consumption of the machines in injection molding lines. To address these matters, as first step, it is necessary to appropriately evaluate the productivity and energy consumption in production lines. Concerning studies on evaluation of energy consumption of injection molding machine, there were three types of the studies. The first type is to focus on evaluating energy consumption of physical phenomenon in injection molding processes such as plastic resin dissolution phenomenon, plasticization phenomenon and so on

adfa, p. 1, 2011.

(C) Springer-Verlag Berlin Heidelberg 2011 
[1][2][3][4]. The second type is to focus on considering the life cycle Assessment (LCA) in injection molding processes using real measurement data [5][6]. The third type is to focus on simulation methods. Concerning the simulation method, several studies have focused on evaluating productivity and energy consumption in production lines including machining and industrial robot[7][8][9]. As the relations among processes in the injection molding production line are complicated, the simulation methods for production lines did not often consider the injection molding machine. Concerning the simulation method for injection molding processes, there are two studies [10][11]. The first study proposed considering the influence of production conditions and part shape [10]. However, this method focused on only single injection molding machines and did not consider auxiliary machines and multiple production lines to calculate the productivity and energy consumption of the whole production system. The second study proposed a simulation modeling method that defined a relationships among injection molding processes, necessary machines, and auxiliary machines, and defined states and transitions of each machine [11]. However, this simulation modeling method was not implemented in manufacturing system simulation.

In this research, a simulation method for pre-evaluating the productivity and energy consumption is proposed by using the simulation modeling method of the relationship between the machine states and the transitions in the injection molding production line. The proposed simulation method is implemented in manufacturing system simulation. Case studies to evaluate the effectiveness of the proposed simulation method were examined.

\section{Proposal of the evaluation method of productivity and energy consumption of an injection molding production line}

Productivity and energy consumption of a production line can be calculated by integrating the work time or energy consumption of each system constituting the production line. The work time and energy consumption in each system changes over time, often in response to the state and state transitions in each system. Therefore, the evaluation of productivity or energy consumption requires a model linking the state, state transition, and energy consumption for each process. The production line of injection molding consists of material supplying processes, material drying processes, material plasticizing processes, producing processes, and product removing processes. These processes are executed by material loaders, material dryers, injection molding machines, and product take-out machines. In previous research, a state transition model was proposed for organizing the relations between the machine states and state transitions in an injection molding production model constituting these five processes. In the proposed state transition model, the state in each process, the state transition, as well as the inter-process sub-states' relations are organized as shown in Figure 1.

To evaluate the productivity of a production system, we use discrete simulation. In particular, we simulate the flow of material and information in the production line 
through a discrete-time progression. In this case, the machine states and the state transition in a production system is modeled, and the productivity of the production system is evaluated by grasping the working and non-working states in the system states.

By implementing the state transition model of an injection molding production line that was previously proposed in our present simulation and modeling the state transition over time, it is possible to calculate the production time and throughput amount. Moreover, by assigning energy consumption to each of the system states, the total energy consumption over time can be calculated. Furthermore, by simultaneously evaluating the throughput amount and energy consumption, we are able to calculate the specific energy consumption, which is a representative index for evaluating the productivity and total energy consumption.

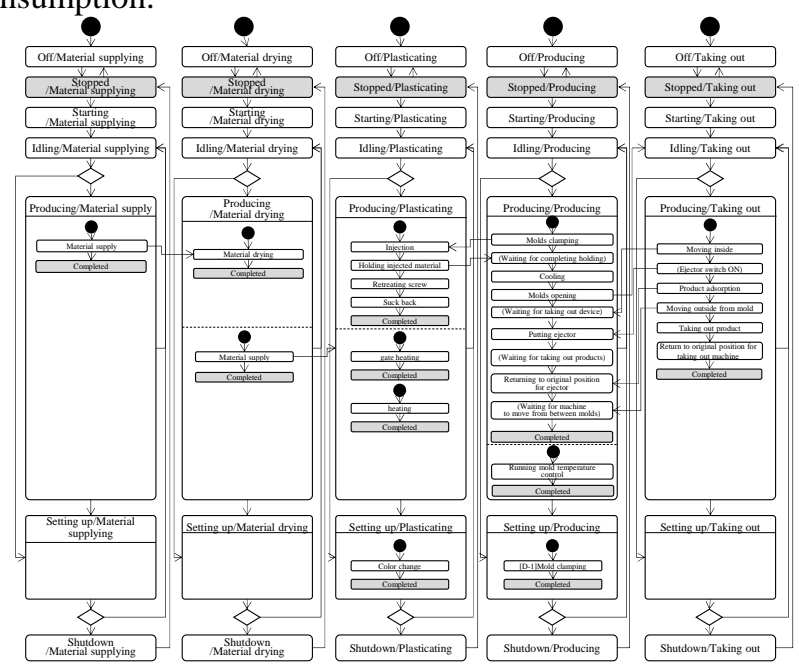

Fig. 1. Injection molding production line’s state transition model.

The specific energy consumption is an index evaluating the amount of energy consumption per product, and it is calculated from the amount of throughput $P$ [product] and the energy consumption amount $E[\mathrm{~J}]$ using equation (1).

$$
U=E / P
$$

We will explain the method of applying an injection molding production line's state transition model to a simulation.

First, we implement a state transition model of each process. For every process, a computer model based on a simulation is implemented, and information regarding state transitions at each state and sub-state is programed in the model. Overall, we implement this model for five processes.

Next, the constraints for the state transitions of each process are implemented. Since an injection molding machine and auxiliary machines in the production line work together, the proposed state transition model has procedural relations and constraints relating to the defined state transitions. In the procedural relations of state transitions, 
there are state and sub-state transitions in each process that serve as constraints for the generation of state transitions in other processes. Hence, with simulations, by implementing an imaginary signal for the state and sub-state transitions in each process and establishing a program for the process and other processes' states and sub-states to incorporate those signals, the procedural relations and restrictions in the state transitions are modeled.

Furthermore, a program for managing the input and output of information at each state is implemented. For each state of a process, the energy consumption is provided as input data. Moreover, a program that provides information related to productivity and energy consumption as output by simultaneously generating information on energy consumption and state transition over time is used.

Based on the above procedures, a state transition model is implemented in a simulation. The implemented simulation simultaneously generates time-labeled state transition information as well as time-labeled state and energy consumption information, and it evaluates productivity as well as energy consumption. A summary of the evaluation method based on the implemented simulation is shown in Figure 2. The state transition model in the production line is implemented in WITNESS which is a modeling tool for production system based on a discrete event simulation. WITNESS comprises basic models to represent machine behavior and can be extended using Visual Basic to create the required production system models.

\section{$3 \quad$ Case study}

In this chapter, the proposed simulation method is used to assess whether the method successfully yields evaluation indicators regarding productivity and energy consumption. To verify the performance of the proposed method for different sys-tem boundaries, the following three cases were studied. Case study 1: single injection molding machine, Case study 2: one injection molding line including a single injection molding machine with auxiliary machines, and Case study 3 : two parallel injection molding lines.

The following assumptions are made in this case study: six product items are processed in each production line, the lot size of each item is fixed, a production line produces one lot for each of the six product items every working day, changeover of molding die or material occurs during lot switching, and the simulation period is one-day operation from machine turn on to machine shutdown, i.e., about $10 \mathrm{~h}$.

The energy consumption of each machine state was measured. The measured da-ta were different for each product item owing to changing production conditions, such as the cycle time and the amount of material usage.

In this case study, we confirmed reproducibility of the proposed method. When we applied the simulation model to a product item whose lot size was one, the model correctly yielded the state transition times and energy consumption of the machines. In addition, by adopting similar approaches not only for different product items but also for different lots, we could confirm reproducibility of the proposed method. 
In this case study, the measured production time and energy consumption values were input to the state transition model in the injection molding production line. For simulation model validation, we examined whether the results of the evaluation indicators were in accordance with the results of manual calculations.

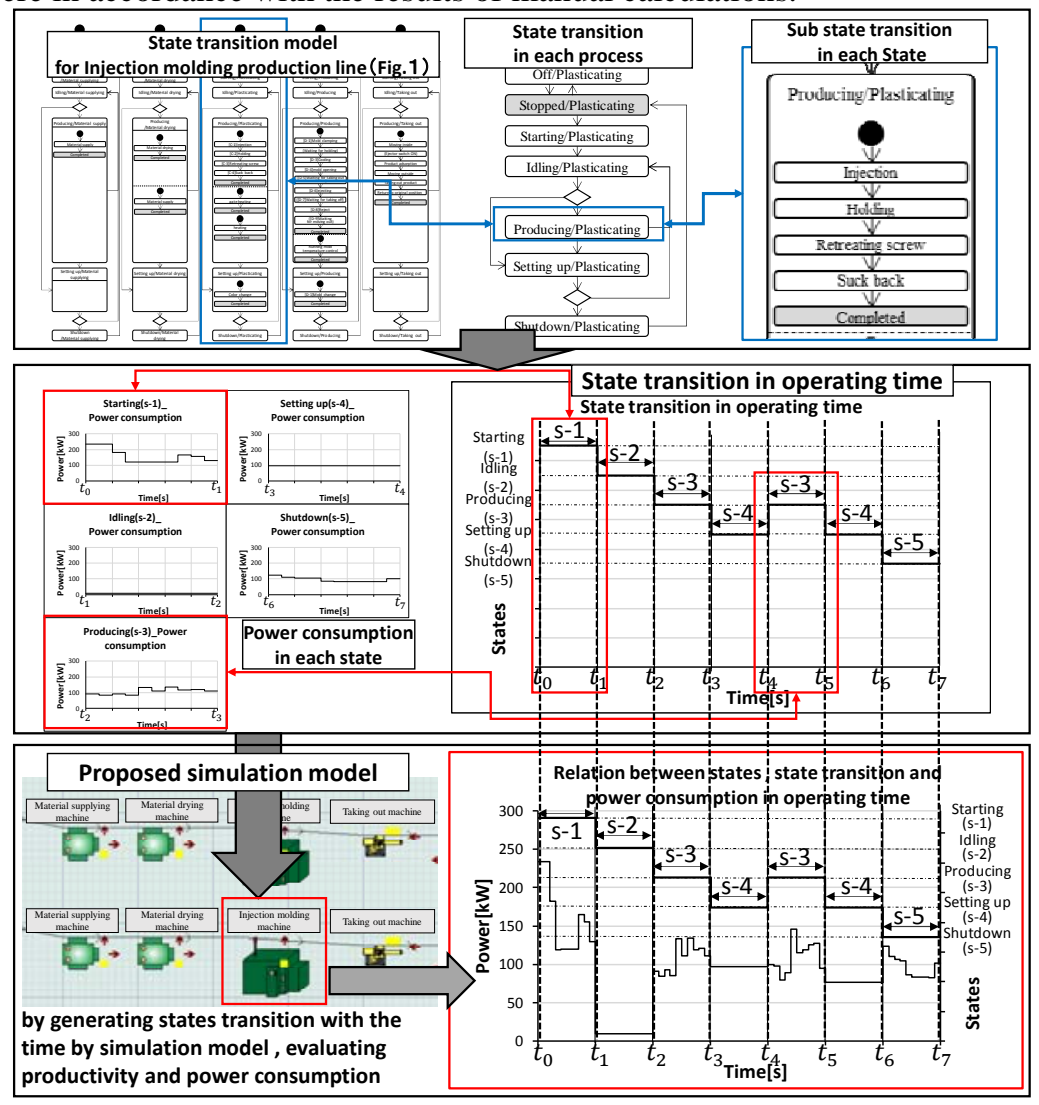

Fig. 2. Summary of the proposed evaluation method.

\subsection{Case study 1}

In this section, the material plasticizing and manufacturing process attempted by the injection molding machines are targeted to access the proposed evaluation method. The simulation results are shown in Table 1 and Figure 3.

\subsection{Case study 2}

In this section, we verify the evaluation method with respect to the injection molding production line of case study 1 incorporating the material supplying process, material drying process, and product taking-out process. The implementation conditions are the same as in case study 1 . The results are shown in Table 1 and Figure 3. 
Table 1. Calculated evaluation index for consumption energy and productivity.

\begin{tabular}{|c|c|c|c|c|c|c|}
\hline \multirow[b]{2}{*}{ classification } & \multirow[b]{2}{*}{ evaluation index } & \multirow[b]{2}{*}{ unit } & \multirow{2}{*}{$\begin{array}{l}\text { Cases study } 1 \\
\text { Machine No.1 } \\
\end{array}$} & \multirow{2}{*}{ 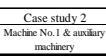 } & \multicolumn{2}{|c|}{\begin{tabular}{|c|} 
Case study 3 \\
\end{tabular}} \\
\hline & & & & & & \\
\hline \multirow{8}{*}{ 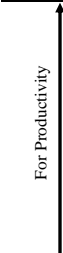 } & Total ouput & product & 442 & 442 & 442 & 602 \\
\hline & Operating time & $\mathrm{s}$ & 33084 & 33084 & 33084 & 30799 \\
\hline & 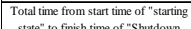 & $\mathrm{s}$ & 31682 & 31682 & 31682 & 28204 \\
\hline & $\begin{array}{l}\text { Producing time } \\
\end{array}$ & $\mathrm{s}$ & 25082 & 25082 & 25082 & 25204 \\
\hline & Total time to Start-up and Shurdown & $\mathrm{s}$ & 1402 & 1402 & 1402 & 2595 \\
\hline & Total time to Set up & $\mathrm{s}$ & 6600 & 6600 & 6600 & 3000 \\
\hline & Throughput per unit time & products & 0.01 & 0.01 & 0.01 & 0.02 \\
\hline & $\begin{array}{l}\text { Utilization ratio } \\
\end{array}$ & $\%$ & 79.17 & 79.17 & 79.17 & 89.36 \\
\hline & Specific energy consumotion & kWhproduct & 2.32 & 2.61 & 2.61 & 1.88 \\
\hline \multirow{5}{*}{ 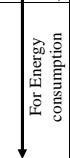 } & Energy consumption in producing time & $\mathrm{kWh}$ & 816 & 816 & 816 & 895 \\
\hline & Energy consumption in waiting time & $\mathrm{kWh}$ & 207 & 207 & 207 & 113 \\
\hline & Total energy consumption & $\mathrm{kWh}$ & 1023 & 1155 & 1155 & 1135 \\
\hline & $\begin{array}{l}\text { Maximum instantaneous power } \\
\text { consumption }\end{array}$ & $\mathrm{kw}$ & 248.00 & 259.25 & 259.25 & 242.34 \\
\hline & Maximum demand power & $\mathrm{kw}$ & 146.62 & 159.63 & 285.00 & 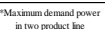 \\
\hline
\end{tabular}
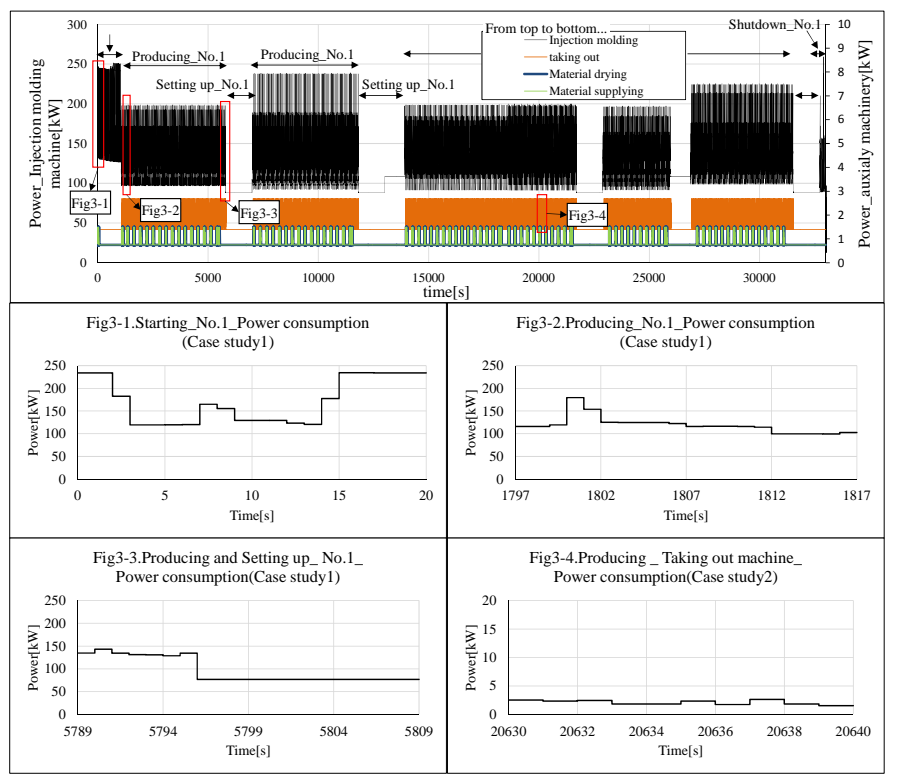

Fig. 3. List of the computed results for electricity consumed in case study.

\subsection{Case study 3}

In this section, we verify a production system with two injection molding production lines, such as those used in case study 2 . The results of the simulations are shown in Table 1.

In addition, Case study 3 also attempts change the production lot sequence so that a better production plan takes into account both the productivity and electricity consumption can be considered. The lot sequence in the production line with injection molding machine No. 2 is fixed. On the other hand, the lot sequence in the production line with injection molding machine No.1 is changed. The original lot sequence in the line with 
injection molding machine No.1 is item No. 1, 2, 3, 4, 5, and 6. The better sequence is item No. 5, 6, 4, 3, 1, and 2. By changing the lot sequence in the production line, the specific energy consumption reduces from $2.19 \mathrm{kWh} /$ product to $1.93 \mathrm{kWh} /$ product. The maximum electricity demand, which is defined as the mean electricity consumption in 30-min intervals in the two production lines, decreases from $285 \mathrm{~kW}$ to $249 \mathrm{~kW}$.

\subsection{Results of the Case study}

In case study 1, we evaluated whether the proposed simulation-based evaluation method can evaluate the productivity and energy consumption of the material plasticizing and producing processes conducted by the injection molding machines. The state transition in each process can be modeled as the simulation progresses, confirming the fact that the proposed method can be used to evaluate productivity. Moreover, it was confirmed that the energy consumption in each state can be calculated. Furthermore, by generating the system state and the energy consumption simultaneously over time, the specific energy consumption, which is a representative index for simultaneously evaluating productivity and energy consumption, could be calculated. Therefore, in case study 1 , the effectiveness of the proposed simulation-based evaluation method could be confirmed.

In case study 2, whether the proposed simulation-based evaluation method can evaluate the productivity and energy consumption of a production line constructed with the addition of three auxiliary machines to case study 1 was verified. As with case study 1 , the state, state transition, and energy consumption vary with time. Moreover, the state transition generation in other processes following the state transition of each process could be modeled. Hence, in case study 2, the effectiveness of the proposed simulationbased evaluation method could be confirmed.

In case study 3, whether it is possible to evaluate the productivity and energy consumption of a production system with two production lines constructed from injection molding machines and three auxiliary machines was verified. Even when the number of production lines increased, evaluations of productivity and energy consumption were possible, as in case study 2. Therefore, in case study 3 , the effectiveness of the proposed simulation-based evaluation method could be confirmed. Furthermore, we confirmed that the proposed simulation method could evaluate energy consumption of the entire production system, which is one of the important matters of concern when we consider production plans. Thus, the proposed method can be useful for production planning in terms of energy consumption of production systems.

According to the above, the usefulness of the proposed method for simultaneously evaluating productivity and energy consumption by implementing a state transition model for an injection molding production line through a simulation was confirmed.

\section{Conclusion}

This research presented a method for simultaneously evaluating the productivity and energy consumption of an injection molding production line. The method proposed 
method involves application of the state transition model of an injection molding production line to a simulation. Different case studies were examined, and the effectiveness of the proposed evaluation method was confirmed. The proposed method could efficiently evaluate the productivity and energy consumption using different system boundaries of the production system, such as a single injection molding machine, single injection molding machine with auxiliary machines, and multiple production lines. In future, we will attempt to develop a method for reducing the electrical cost of maintaining specific energy consumption in an injection molding production line.

\section{Reference}

1. Chien, Joshua M., Dornfeld, David. (2013) Semi-empirical Modeling of the Energy Consumed during the Injection Molding Process. In Re-engineering Manufacturing for Sustainability, Springer, Singapore, pp 297-302

2. Ribeiro, I., Peças, P., Henriques, E. (2012) Assessment of energy consumption in injection moulding process. In Leveraging Technology for a Sustainable World, Springer, Heidenberg, pp 263-268

3. Weissman, A., Ananthanarayanan, A., Gupta, S. K., Sriram, R. D. (2010) A systematic methodology for accurate design-stage estimation of energy consumption for injection molded parts. In ASME 2010 International Design Engineering Technical Conferences and Computers and Information in Engineering Conference, American Society of Mechanical Engineers, pp 525-536

4. Mattis, J., Sheng, P., DiScipio, W., Leong, K. (1996) A framework for analyzing energy efficient injection-molding die design. In Electronics and the Environment, 1996. ISEE1996., Proceedings of the 1996 IEEE International Symposium on, IEEE, pp 207-212

5. Thiriez, A., Gutowski, T. (2006) An environmental analysis of injection molding. In Proceedings of the 2006 IEEE International Symposium on Electronics and the Environment, 2006, IEEE, pp 195-200

6. Elduque, A., Elduque, D., Javierre, C., Fernández, Á., Santolaria, J. (2015) Environmental impact analysis of the injection molding process: analysis of the processing of high-density polyethylene parts. Journal of Cleaner Production Vol. 108, pp 80-89

7. Beier, J., Thiede, S., Herrmann, C. (2017) Energy flexibility of manufacturing systems for variable renewable energy supply integration: Real-time control method and simulation. Journal of Cleaner Production Vol. 141, pp 648-661

8. Herrmann, C., Thiede, S., Kara, S., Hesselbach, J. (2011) Energy oriented simulation of manufacturing systems - Concept and application. CIRP Annals - Manufacturing Technology 60, pp 45-48. doi:10.1016/j.cirp.2011.03.127

9. Sakuma, T., Hibino, H. and Yamaguchi, M (2013) Manufacturing system simulation for evaluation of productivity and energy consumption, Transactions of the Japan Society of Mechanical Engineers, Series C, Vol.79, No.798, pp.178-189

10. Madan, J., Mani, M., Lee, J. H., \& Lyons, K. W (2015) Energy performance evaluation and improvement of unit-manufacturing processes: injection molding case study. Journal of Cleaner Production, Vol 105, pp 157-170

11. Takasaki, R. Hibino, H. Kaifuku, K. Nishitani, K (2017) Study of Modeling and Simulation Injection Molding Machines for Evaluation of Productivity and Energy Consumption. 1st report, Suggestion of the basic model. JSME No.17-8 Manufacturing Systems Divisions conference 2017, pp 39-40 